\section{B A Institute of \\ YK Business Administration \\ 六下 \\ Karachi \\ Leadership and Ideas for Tomorrow}

\section{Business Review}

Volume 7 Issue 1 January-June 2012

$1-1-2012$

\title{
Influence of age and gender on the emotional intelligence of managers
}

\author{
L. K. Singh \\ Kumaun University, Bhimtal, Nainital (Uttarakhand), India \\ Ruchi Srivastava \\ Gayatri College of Management, Jamadarpalli, Sambalpur (Orissa), India
}

Follow this and additional works at: https://ir.iba.edu.pk/businessreview

Part of the Business Intelligence Commons, Personality and Social Contexts Commons, and the Public Administration Commons

\section{(c) (i)}

This work is licensed under a Creative Commons Attribution 4.0 International License.

\section{Recommended Citation}

Singh, L., \& Srivastava, R. (2012). Influence of age and gender on the emotional intelligence of managers. Business Review, 7(1), 128-141. Retrieved from https://doi.org/10.54784/1990-6587.1307 


\title{
DISCUSSION
}

\section{Influence of Age and Gender on the Emotional Intelligence of Managers}

\author{
L.K. Singh \\ Kumaun University, Bhimtal, Nainital (Uttarakhand), India \\ Ruchi Srivastava \\ Gayatri College of Management, Jamadarpalli, Sambalpur (Orissa), India
}

\begin{abstract}
Organizations are made up of people and function through people. Without people organizations cannot exist. The resources of men, money, materials and machines are collected, coordinated and utilized through people. Therefore, we can say that people are the most significant resource of any organization. However globalization has brought in more competition. Now the organizations are on a race to become the market leader and there is high competition for survival. All these factors have brought the employees under fear, sense of insecurity and high stress due to which they become nervous, chronically worried, depressed and emotionally instable. They are easily provoked to anger, unable to relax and may be uncooperative. Emotional intelligence is the only tool that can help a person control emotions, anger and stress. With the emotional intelligence skills we can control emotions like anxiety, low motivation, depression and stress of the employee. This research paper attempts to study the effects of age and gender on the emotional intelligence of a manager and its impact on his or her leadership qualities.
\end{abstract}

\section{Introduction}

It has been observed that liberalization, privatization and globalization have highly influenced the human factor. Globalization has introduced the strategies of downsizing of organization structure, employee retrenchment, lay off, insecurity, and high level of competition. Nowadays, organizations are on a race to become the market leader .All these factors have brought changes in the organizational environment .Now employees are working longer hours, under fear, a sense of insecurity and high stress levels. This is somehow affecting their performance.

The presence of stress at work is almost inevitable in many jobs. When pressure begins to build up, it can cause adverse strain on a person's emotions, thought processes and physical conditions. When stress becomes excessive, employees develop various symptoms that can harm their job performance and health and even threaten their ability to cope with environment. People who are stressed may become nervous and chronically worried and depressed, emotionally instable and lose their level of motivation. High pressure and tension also leads to physical disorders and various degenerative diseases of heart, kidneys, blood vessels and other parts of the body. It can result in angina, tension and headaches. Therefore 
it is important that stress both on and off the job be kept at a level low enough for most people to tolerate without developing either emotional or physical disorders.

Nowadays pressure and competition has become the part and parcel of life leading to emotional instability, tension, depression and others. To overcome these, Emotional Intelligence has emerged as a ray of hope for employees. With the right emotional intelligence skills, one can control issues like anxiety problems, addiction and many more.

\section{The importance of Emotional Intelligence}

Emotional intelligence, often measured as an emotional quotient, is described as the ability, capacity, skill or a self-perceived ability, to identify, assess, and manage the emotions of one's self, of others and of groups. According to Roger Elliot, "Emotional intelligence is the capacity for recognizing our own feelings and those of others, for motivating ourselves, and for managing emotions well in ourselves and others." Thus we can say that the emotional intelligence quotient is defined as a set of competencies demonstrating the ability one has to recognize his or her behaviors, moods, and impulses, and to manage the, best according to the situation. The term Emotional Intelligence was popularized by Daniel Goleman. According to Goleman, individuals are born with a general emotional intelligence which determines their potential for learning emotional competencies. Goleman's model outlines four main EI constructs:

i) Self awareness: - The ability to read one's emotions and recognize their impact while using the gut feeling to guide decision.

ii) Self management: - The ability to control one's emotions and impulses and adapt to changing circumstances.

iii) Social awareness: - The ability to sense, understand, and react to others emotions while comprehending social networks.

iv) Relationship management: - The ability to inspire, influence and develop others while managing conflict.

Modern organizations are highly volatile, dynamic and demand higher productivity. Tasks cannot simply be accomplished individually or by working with others in fixed or routine ways. Only those who can respond to the mounting challenges and be open to innovate can survive. These jobs involve understanding, communicating, empathizing with and learning from team members. The skills required to succeed at these jobs with a future require a high degree of intellectual ability as well as EI. Knowledge and skill may help someone get in to the position, but it takes an emotional understanding of oneself and those around to emerge triumphant. Hence, employees too are called on to balance their skills with the qualities of the head and heart.

As the ability to get things done through people is the vital task of the manager, EQ is an important factor. If managers do not balance their IQ skills with EI like understanding and empathy, employees might feel insecure and unappreciated. At times they can even feel underestimated, criticized, and disrespected. These negative feelings can result in dissatisfaction leading to absenteeism, passivity, lack of productivity and attrition. As employees with desired potential are scarce, only those who are adept in retaining employees can excel in their jobs.

Hence companies are laying heavy emphasis on the need to integrate both the skills of the head and heart to manage employees better. The managers and professionals are 
designing programs to educate people about the relevance of EI in effective management of people. This helps in creating an environment where employees feel trusted, valued, stay motivated, respected and rewarded leading to minimizing stress and reduce turnover. Even, recruitment and selection processes are geared towards selecting those who can balance the skills of the head and heart

A well-developed emotional intelligence allows a leader to restrain less productive feeling like anger and self doubt and focus on goals with more positive feeling like self confidence and open communication. The result is higher team productivity. Thus we can say a human being can alter his life by altering his level of Emotional Intelligence.

\section{Statement of the problem:}

Employees are the asset of the organization. The enhanced importance of employees' contribution in increasing the productivity of the firm has provoked an interest in examining their utility. Employees, whether working in organized or unorganized industries, cannot give better productivity without proper motivation, satisfaction and emotional stability. The manager of the modern times performs a complex task of unifying the labour and other resources so as to achieve the overall organizational goals. In this process, he has to deal with his superiors and subordinates and also with the factors affecting the external and the internal organizational environment. He has to make the best use of his position so that within the framework of managerial functions that he performs, he can also train his subordinates that organizational adaptability to environment increases and the organization is able to survive in his modern era of tough competition.

Thus, we see that managers who act as leaders of the organizations have to deal with various complexities, threats, stress and high competition for survival. This generates in them a sense of depression, nervousness, emotional instability, which ultimately hampers their efficiency and productivity. It has been felt that emotional intelligence may help the leaders in self-control, empathy, teamwork, self- confidence, analytical thinking, conceptual thinking and many other leadership traits. Realizing the importance of emotional intelligence it was thought that, do age and gender influence the emotional intelligence of the manager? Keeping this in view, an attempt to conduct a study in this area was made to study the influence of age and gender on emotional intelligence of the manager.

\section{Objectives of the study}

1. The objective of research was to examine the impact of age on the Emotional Intelligence and leadership behavior of the managers, through the application of a systematic and scientific way.

2. The research also attempted to study the impact of gender on the Emotional Intelligence and leadership qualities of the manager.

\section{Research Design}

For the research study, the Descriptive Research Design was selected .The techniques used in descriptive research design are: a) Primary data b) Secondary data. For collecting primary data, a structured questionnaire was made consisting of close ended questions and Likert scale based questions.

\section{Sampling Design}

A sample design is a definite plan for obtaining a sample from a given population. It refers to the technique or the procedure the researcher would adopt in selecting items for 
the sample. Sample design may as well lay down the number of items to be included in the sample i.e. the size of the sample.

\section{Population}

The first step in developing any sample design is to clearly define the set of objects i.e. from where the respondents will be taken.

For the proposed study, the employees of various types of the organizations (private and public) shall constitute the population.

\section{Sampling Unit}

The sampling unit for the proposed study is the manager. A manager can be defined as a person who is giving instructions to more than two subordinates

\section{Sample size}

The total number of units in a sample. The sample size proposed for the study is 527.

\section{Research Area}

The area of Lucknow Nigam has been considered as research area. In this study 527 employees have been treated as study population. A sample of 527 employees was selected in this study through simple random sampling method.

\begin{tabular}{|c|c|c|}
\hline S. No. & Category of Employee & No. o f employees \\
\hline 1. & Private & 233 \\
\hline 2. & Public & 294 \\
\hline
\end{tabular}

\section{Hypothesis Testing}

In this research study we have formulated certain hypothesis and sub hypotheses which are as follows:

\section{Hypothesis: The behavior of the employee is affected by the Emotional Intelligence}

The behavior of an employee is influenced and varies with age and gender. They are the important determinants of the behavior of the employees hence to analyze the effect of emotional intelligence on the behavior of the employees; an attempt is made to study the impact of age and gender on emotional intelligence. For analyzing the impact of emotional intelligence on the behavior of the employee various statistical tools are used like Mean, SD, level of significance, t-test, ANOVA.

\section{Age wise Analysis of Respondents and its impact on EI and Leadership}

Having emphasized the need of studying the level of Emotional Intelligence in the managers, we choose various five groups of age upto 30, 30-40, 40-50, 50-60 and above 60 years for the research study. The impact of age on the level of emotional intelligence and on the behavior, performance, leadership qualities and other personal characteristics of managers has been studied. As a researcher, I had two objectives in this regard: first to 
determine which segment or subgroup has the most high degree of emotional intelligence and secondly the impact of emotional intelligence on the leadership qualities as per age wise. Once these profiles are constructed, they can be used by the organization for the right selection of managers and for training of emotional intelligence to the managers. The emotional intelligence has drastically influenced the organization. The degree or level of emotional intelligence is found to influence the behavior of the manager. Therefore this study will fulfill the gap and highlight the different influential factor. This study will assist the organization in the recruitment, selection and training of the manager by showing the fact that which segments have the high degree of emotional intelligence and how it is influencing the behavior of the managers and their leadership qualities and how these leadership qualities are influencing the efficiency and effectiveness of the organization.

Sub hypothesis 1: Emotional intelligence, leadership drivers and leadership quality is affected by age.

Table 1: Mean, SD and ANOVA for Emotional Intelligence and Leadership Drivers

\begin{tabular}{|c|c|c|c|c|c|c|c|c|c|c|c|c|c|}
\hline \multirow{3}{*}{$\begin{array}{l}\text { S. } \\
\text { No. }\end{array}$} & \multirow{3}{*}{ Dimension } & \multicolumn{12}{|c|}{ Age Group } \\
\hline & & \multicolumn{2}{|c|}{$\begin{array}{l}\text { Upto } 30 \\
(n=28)\end{array}$} & \multicolumn{2}{|c|}{$\begin{array}{c}30-40 \\
(n=174)\end{array}$} & \multicolumn{2}{|c|}{$\begin{array}{c}40-50 \\
(n=163)\end{array}$} & \multicolumn{2}{|c|}{$\begin{array}{c}50-60 \\
(n=144)\end{array}$} & \multicolumn{2}{|c|}{$>60(n=18)$} & \multicolumn{2}{|c|}{ ANOV } \\
\hline & & Mean & SD & Mean & SD & Mean & SD & Mean & SD & Mean & SD & $\mathbf{F}$ & $\mathbf{P}$ \\
\hline \multicolumn{14}{|c|}{ Emotional Intelligence } \\
\hline 1. & Self awareness & 2.34 & 0.53 & 2.08 & 0.46 & 2.19 & 0.42 & 2.28 & 0.56 & 1.83 & 0.38 & 6.594 & $<0.001$ \\
\hline 2. & Self regulation & 2.23 & 0.44 & 2.02 & 0.51 & 2.09 & 0.41 & 2.35 & 0.56 & 2.20 & 0.38 & 10.378 & $<0.001$ \\
\hline 3. & Self motivation & 2.20 & 0.44 & 1.92 & 0.44 & 2.02 & 0.39 & 2.09 & 0.57 & 1.94 & 0.38 & 3.918 & 0.004 \\
\hline 4. & $\begin{array}{l}\text { Social } \\
\text { competence }\end{array}$ & 2.15 & 0.43 & 2.04 & 0.48 & 2.02 & 0.36 & 2.13 & 0.62 & 1.80 & 0.33 & 2.779 & 0.026 \\
\hline & Total EI & 2.23 & 0.36 & 2.02 & 0.39 & 2.08 & 0.31 & 2.21 & 0.49 & 1.94 & 0.32 & 6.572 & $<0.001$ \\
\hline \multicolumn{14}{|c|}{ Leadership Drivers } \\
\hline 1. & Motiv & 2.08 & 0.55 & 1.81 & 0.56 & 1.97 & 0.50 & 2.05 & 0.66 & 1.78 & 0.41 & 4.396 & 0.002 \\
\hline 2. & $\begin{array}{l}\text { Conflict } \\
\text { management and } \\
\text { team building }\end{array}$ & 1.87 & 0.45 & 1.84 & 0.41 & 1.90 & 0.42 & 1.92 & 0.50 & 1.78 & 0.38 & 0.880 & 0.476 \\
\hline 3. & Communication & 1.99 & 0.45 & 1.91 & 0.52 & 1.97 & 0.44 & 2.04 & 0.71 & 1.91 & 0.48 & 1.173 & 0.322 \\
\hline 4. & $\begin{array}{l}\text { Work / } \\
\text { Performance }\end{array}$ & 1.94 & 0.45 & 1.74 & 0.40 & 1.87 & 0.45 & 1.86 & 0.65 & 1.58 & 0.43 & 3.238 & 0.012 \\
\hline & tal LD & 1.97 & 0.33 & 1.83 & 0.38 & 1.93 & 0.33 & 1.97 & 0.54 & 1.76 & 0.31 & 3.219 & 0.013 \\
\hline & verall Scores & 2.10 & 0.33 & 1.92 & 0.36 & 2.01 & 0.30 & 2.09 & 0.49 & 1.85 & 0.29 & 5.099 & $<0.001$ \\
\hline
\end{tabular}


Figure 1: Association between Age and Emotional Intelligence

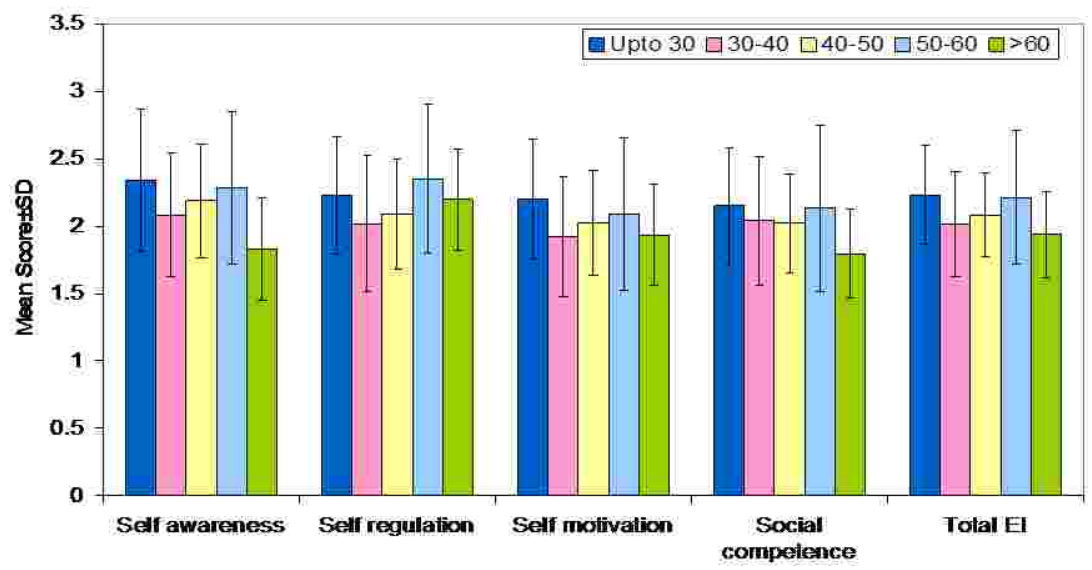

Figure 2: Association between Age and Leadership Drivers

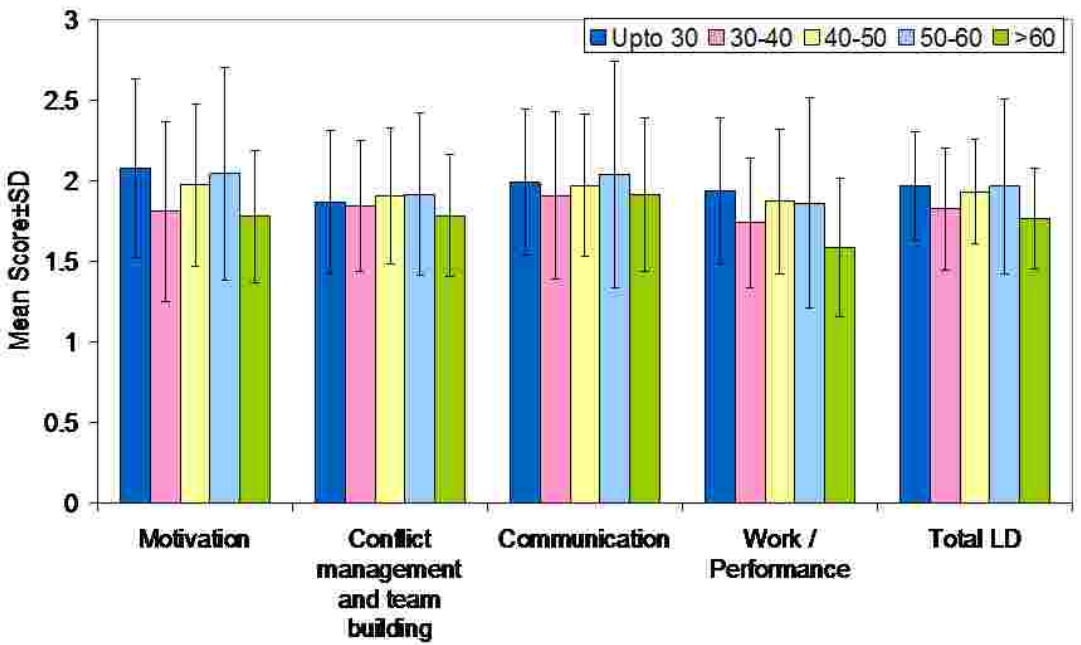




\section{Figure 3: Association between Age and Overall Leadership Scores}

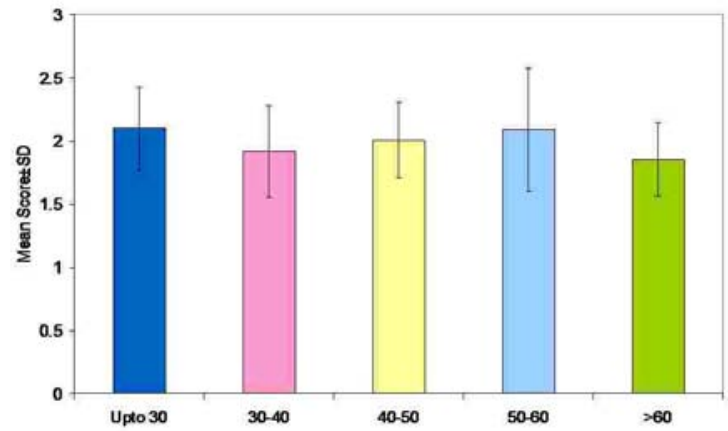

\section{Inference}

For all the items under emotional intelligence as well as overall emotional intelligence scores, the calculated F-value was above critical F-value ( $\mathrm{F}>2.70)$, the sub-hypothesis that age affects the emotional intelligence is accepted. For leadership drivers for two-items the F-value was below critical value of 2.70 , hence the hypothesis was rejected. However for the remaining two variables as well as overall scores, the calculated F-value was above critical F-value hence the hypothesis was accepted. For overall leadership quality scores, the calculated F-value was above critical F-value hence the hypothesis was accepted.

\section{Findings}

- A significant difference in mean scores among different age groups was observed for all the dimensions as well as total scores of emotional intelligence $(\mathrm{F}>2.70$; $\mathrm{p}<0.05)$.

- It was observed that for all the dimensions, the mean scores of $>60$ years age group were minimum for the dimension self awareness, social competence and total score of Emotional intelligence

- $\quad$ For the dimensions self regulation and self motivation, the mean scores of age group 30-40 years were minimum.

For different dimensions, the maximum scores were observed for age group up to 30 years and 50-60 years.

The scores were observed to be of higher order for the age groups up to 30 and 5060 years while for the age groups $30-40,40-50$ and $>60$ years, they were observed to be of lower order.

Though age wise, difference in mean scores for different dimensions of emotional intelligence as well as overall intelligence were observed yet there was no linear relationship between age and emotional intelligence. It was inferred that at different life stages, the emotional experiences of the individual affected the emotional intelligence scores with varied intensity. 
Gender wise Analysis of Respondents and its impact on Emotional Intelligence and Leadership

In the research we attempt to study the impact of gender on the level of emotional intelligence, their behavior, performance and leadership qualities. The objective of study was to determine if there is any difference between Emotional intelligence and if yes to what extent and how much is it influencing the leadership qualities of the respondents. It also aimed to study which dimensions of emotional intelligence and the leadership is found stronger in males and females. This will help the organization in recruitment, selection and assigning the job responsibilities to the managers.

Sub hypothesis 2: Emotional intelligence, leadership drivers and leadership quality is affected by gender.

Critical "t"-value: 1.96

Table 2: Mean, SD and Student "t"-test for Emotional Intelligence and Leadership Drivers

\begin{tabular}{|c|c|c|c|c|c|c|c|}
\hline \multirow{3}{*}{$\begin{array}{l}\text { S. } \\
\text { No. }\end{array}$} & \multirow{3}{*}{ Dimension } & \multicolumn{4}{|c|}{ Gender } & \multirow{2}{*}{\multicolumn{2}{|c|}{$\begin{array}{c}\text { Significance of } \\
\text { difference } \\
\text { (Student " } t \text { "-test) }\end{array}$}} \\
\hline & & \multicolumn{2}{|c|}{ Male $(n=43)$} & \multicolumn{2}{|c|}{ Female $(n=95)$} & & \\
\hline & & Mean & SD & Mean & SD & "t" & $\mathbf{P}$ \\
\hline \multicolumn{8}{|c|}{ Emotional Intelligence } \\
\hline 1. & Self awareness & 2.20 & 0.48 & 2.06 & 0.53 & 2.616 & 0.009 \\
\hline 2. & Self regulation & 2.16 & 0.50 & 2.11 & 0.53 & 0.933 & 0.351 \\
\hline 3. & Self motivation & 2.04 & 0.46 & 1.89 & 0.48 & 2.826 & 0.005 \\
\hline 4. & Social competence & 2.04 & 0.50 & 2.15 & 0.43 & -1.938 & 0.053 \\
\hline & Total EI & 2.11 & 0.40 & 2.05 & 0.41 & 1.312 & 0.190 \\
\hline \multicolumn{8}{|c|}{ Leadership Drivers } \\
\hline 1. & Motivation & 1.93 & 0.59 & 1.99 & 0.52 & -0.998 & 0.319 \\
\hline 2. & $\begin{array}{l}\text { Conflict management } \\
\text { and team building }\end{array}$ & 1.88 & 0.45 & 1.87 & 0.42 & 0.193 & 0.847 \\
\hline 3. & Communication & 1.99 & 0.55 & 1.87 & 0.54 & 1.929 & 0.054 \\
\hline 4. & Work / Performance & 1.82 & 0.49 & 1.81 & 0.55 & 0.099 & 0.921 \\
\hline & Total LD & 1.90 & 0.41 & 1.89 & 0.44 & 0.373 & 0.709 \\
\hline & Overall Scores & 2.01 & 0.38 & 1.97 & 0.41 & 0.889 & 0.375 \\
\hline
\end{tabular}


Figure 4: Association between Gender and Emotional Intelligence

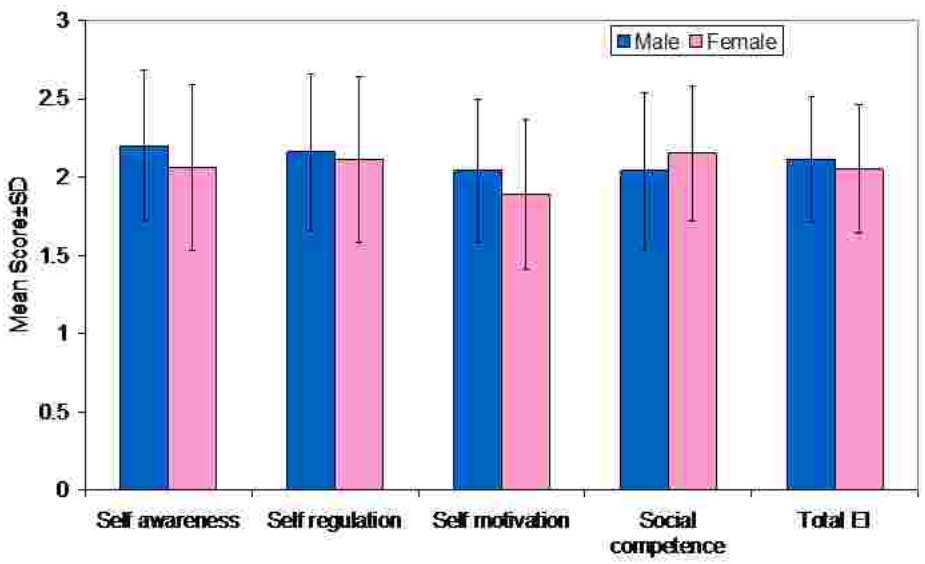

Figure 5: Association between Gender and Leadership Drivers

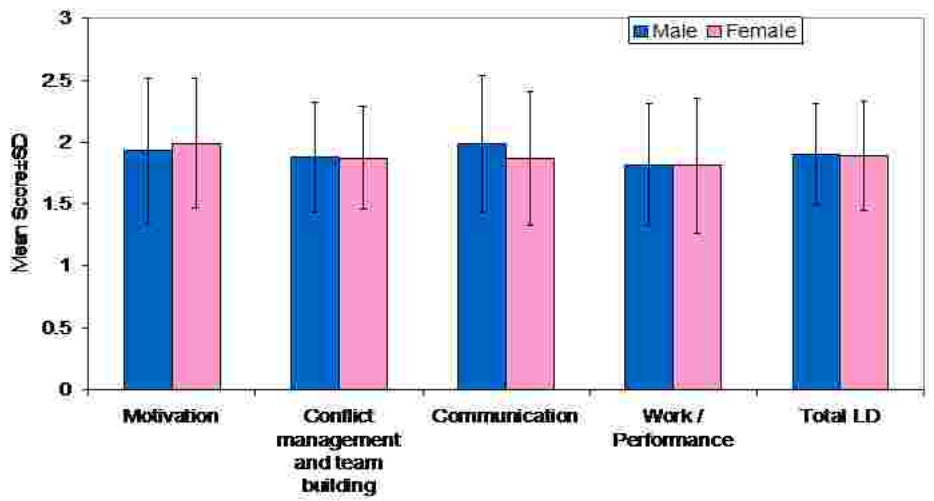


Figure 6: Association between Gender and Overall Leadership Scores

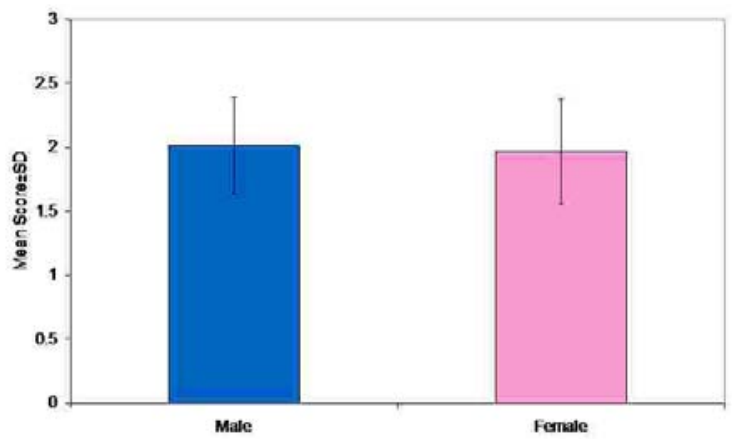

\section{Findings}

Though the mean scores for dimensions self awareness and self motivation were observed to be significantly higher amongst males as compared to females (calculated t-value above critical t-value), yet no significant difference between two genders was observed for overall emotional intelligence as well as for any of the dimensions of leadership drivers independently or collectively.

- Overall, there was no significant difference between two genders as regards the total scores for leadership.

\section{Inference}

Though item wise evaluation revealed a significant difference between two genders for two items of emotional intelligence, yet overall no impact was observed for emotional intelligence as well as for leadership drivers. For leadership quality too, no significant difference between two genders was observed. The sub-hypothesis\#7 is rejected (calculated t-value below critical t-value) and alternate hypothesis that gender has no effect on emotional intelligence, leadership drivers and leadership qualities.

The analysis of our respondents as per the age wise is concerned, 5.3 percent of the respondents were of age up to 30 years, 33 percent of the respondents were between 30 to 40 years and 30.9 percent of the respondents were in between 40 to 50 years, 27.3 percent were in between 50 t0 60 years and 3.4 percent were greater than 60 years. We can say that organizations mostly prefer the managers between 30 to 60 years and among which managers between 30 to 50 years are most desirable. As far gender is concerned 82 percent were male and 18 percent were females so we can say that in the organizations, it is the male who are dominating the post of manager rather than females. 


\section{Discussions and Conclusion}

\section{Age wise Analysis of Respondents and its impact on EI and Leadership Discussion}

- It has been observed that age is influencing the emotional intelligence, leadership drivers and overall leadership quality of the managerial personnel. The finding depicts that there is variation in the emotional intelligence of the managers with the variation in the age. The managers up to 30 years and between 50-60 years are highest in emotional intelligence and overall leadership qualities. They are better in controlling their destructive emotions and able to understand the emotions of other. They are better performers than other age group managers. The managers above 60 years are found to be lowest in Emotional intelligence and the leadership qualities.

- During the survey it was observed that merely 5.3\% of the respondents were below 30 years who were working as the mangers in the organizations which shows that a high qualification, talent and experience is required to become the managers and to achieve such qualification and experience, it requires the time due to which a person reaches at the managerial position after the age of 30 years. This is the reason why the majority of the respondents were from the age group of 30-50 years.

- The findings show that managers above 60 years are found to be lowest in the emotional intelligence and leadership qualities. According to Maslow's hierarchy, men after certain period move beyond the need of achievement and recognition. They move to the stage of self actualization. It is the stage of stress so the organization should organize the psychological session to relax the mind of the managers and utilize their knowledge, abilities and skills in the strategy formulation and implementation. The managers above 60 years are found to be lacking in conflict management, team spirit, poor in communication skill and also lack in sensing others feelings and prospective.

- The research study observed that dimension of self regulation and self-motivation is low in the age group 30-40 years. It is found that managers of age group 30-40 are not able to have self control over the disruptive emotions and impulses and not very flexible in handling change. The managers above $30-40$ years are very aggressive in nature due to which they cannot have a control over their abusive language .To achieve the objective or target they can act unethically. These managers are very pragmatic in nature due to which they lack in new ideas and new initiative. These mangers are dominated with the need of power; these managers should be given the psychological session for enhancing the need of achievement and need of affiliation.

\section{Conclusion}

When we tested the relationship between age and emotional intelligence, it was found that age is influencing the emotional intelligence. It was discovered that managers up to 30 years and managers of having age between 50 -60 years have higher emotional intelligence. The managers up to 30 years and managers of between 50-60 years are found high in self awareness, self regulation and social competence. Due to the high self awareness they realize the link between their feeling and what they say and think which help in controlling their destructive emotions and the emotions of others. Since these managers are high in social competence so we can say that these managers are skilled at winning over the 
people. They respect and relate well to people from varied background. They handle difficult people and tense situations very tactfully. The manager of age in between 40-50 years were found comparatively better than the managers of age between 30-40 years but lower than 50-60 years and managers above 60 years are found to be lowest in emotional intelligence . The age is also influencing the leadership drivers of the managerial personnel. The managers of up to 30 years and managers from 40-60 years are found excellent in the leadership drivers and overall leadership qualities while the managers above 60 years score lowest in the overall leadership qualities while the managers of 30-40 years are better, but they can be much better through EI training sessions. I would like to say that Jafar Shabani, Aishah Hassan and Aminal Ahmad Mazah Baba, Malasia have worked on research paper on "Age as Moderated influence on the link of Spiritual and Emotional intelligence with Mental Health in High School Student and finding of this research show that age has a moderated effect on spiritual and emotional intelligence, so I can say that my research is moving in the right direction and my findings also depicts the effect of age on the Emotional intelligence. My findings have shown that different level of emotional intelligence is found at different level of ages which proves that age is influencing the emotional intelligence.

\section{Gender wise Analysis of Respondents and its impact on Emotional Intelligence and Leadership}

\section{Discussion}

- The findings shows that gender does not influence the emotional intelligence and leadership qualities of the manager, but yet during the research it was observed that the few females were found at the managerial level, the cause could be lack of opportunities provided to the females or less inclination of female managers for higher designation due to more movement, stress and lack of confidence. The organizations should organize some psychological and counseling session for enhancing the self confidence in them and also provide them opportunities of higher promotion so that they can prove their capabilities and talent. The role of women in managerial and administrative positions is of very low magnitude in India. Unlike U.S. where the percentage of women in managerial and administrative positions has risen to almost half (46\%) by the year 2002 (U.S. Bureau of Labor Statistics, 2002). In India, the status is much like the situation in US during 1970s when women held only $18 \%$ of managerial and administrative positions (U.S. Bureau of Labor Statistics, 1982). Although journalists and authors of trade books increasingly assert a female advantage in leadership, whereby women are more likely than men to lead in a style that is effective under contemporary conditions yet the findings in present study do not provide such evidence. These results are in concurrence with the findings of Vecchio's [Leadersh. Q. 13 (2002) 643], who in their meta analysis supported the view that women do not have an upper edge in leadership qualities and style. Similar views were expressed by Eagley and Carli (2003; Leadership Quarterly 14; 807-834).

- The dimensional findings of emotional intelligence show that females are higher in social than males. Females are better in sensing others' feelings and perspectives and they are able to cultivate opportunities through different kinds of people. Females are better in social skill as compared to males. Females are good listener and effective communicator. Females believe in nurturing relationship and thus developing team spirit. Female mangers have the ability to the bound all team members together and create a synergistic effect in the team and leads to higher productivity.

- The mean scores for dimensions self awareness and self motivation were observed 
to be significantly higher amongst males as compared to females which indicates that males are better in recognizing one's emotions and have a strong sense of one's self worth and capabilities. Males have a drive for achievement and try to meet a standard of excellence. Males are found to be initiative and optimistic in pursuing goals despite obstacles and setbacks as compared to females.

- When depth analysis of leadership drivers was undertaken, females were found better in enhancing the motivation level among her subordinates and employees in comparison to males. Males were found to be slightly superior in the communication skill as compared to females, but in overall both gender hold equal stand in leadership qualities.

\section{Conclusion}

When we tested the sub hypothesis that gender influences the emotional intelligence of the manager, it was found that gender does not influence the emotional intelligence. We did not get significant difference between emotional intelligence of male and female, although mean score for dimensions self awareness and self motivation were observed to be significantly higher amongst male as compared to females. It was also concluded that gender does not influence the leadership qualities in the mangers as there was no significant difference two genders as regards the total scores for leadership.

\section{Recommendations}

1. When we tested the relationship between age and emotional intelligence, it was found that age is influencing the Emotional Intelligence. It was discovered that managers up to 30 years and managers of having age between 50 -60 years are having higher emotional intelligence. They are better in controlling their destructive emotions and able to understand the emotions of others. The manager of age in between 40-50 years were found comparatively better than the managers of age between $30-40$ years but lower than 50-60 years and managers above 60 years are found to be lowest in emotional intelligence .

Since it has been found that age is influencing the emotional intelligence of the managers so it is the recommendations to the organization that they should look at age factor before the recruitment or appointment of the managers. The analysis shows that managers having the age in between 50 to 60 years or new generation manager's up to 30 years are found to be emotionally intelligent in handling the situations and stress of the working place. They are found to be excellent in the work performance, communication skills and other leadership qualities. The organizations should avoid the recruitment and selection of the managers above 60 years as they are found to be minimum in emotional intelligence. They are not able to recognize their emotions and neither very confident about their capabilities. The managers of age between 40 to 50 years are found to have certain level of emotional intelligence, but the organization should give EI training for the further enhancement of emotional intelligent behavior and better performance.

2. We have observed that gender do not influence the emotional intelligence and leadership qualities at the managerial position, so the organizations should not make any discrimination on the basis of gender during the recruitment and selection of the managers and in the promotion process of the employee. Female managers are as competent and talented as the male managers. 


\section{References}

Corrie, Catherine, (2003), Becoming Emotionally Intelligent, New York, Network Continuum Education.

George, J.M, (2008), Emotions and Leadership: The Role of Emotional Intelligence, London, Sage Publications.

Goleman, D, (1995), Emotional Intelligence, Los Angeles, Bantam Books publication.

Goleman, D, (1998), Working with Emotional Intelligence, Los Angeles, Bantam Books Publication.

Lupton, D, (1998), The Emotional Self, London, Sage Publication.

Ryback, D, (1998), Putting Emotional Intelligence to Work: Successful; Leadership is More Than IQ, Los Angeles, Bantam Publications.

Singh Dilip, (2006), Becoming Emotionally Intelligent - A professional Guide, London, Sage Publication.

Otham Kadir Abdul, Shah Abdullah \& Ahmad Jasmine (2008), Emotional Intelligence, Emotional Labour and Work Effectiveness in service organizations: A Proposed Model. VISION, Vol 12, Number 01.

Sen Anjana, (2008), Neurology of Emotional Intelligence - Interpreted for Managers. VISION; Vol 12, Number 01.

Bardia Garima, (Oct.2010), Unlocking Emotional Intelligence for sustained Organizational Effectiveness, HRM Review.

Kumar DNS, Janakiram. B, Janakiram, Kulkarni M. Praveen,(April 2009), Emotional Intelligence and Employee performance as an indicator for promotion a study of Automobile Industry in the city of Belgaum Karnataka, India, International Journal of Business Management. Joshi Jyoti,( Oct 2010) ,Emotional Intelligence and Performance Improvement, HRM Review,

It requires considerable intellectual sophistication to deny causal influence to ideas in human affairs. For aside from instinctive and habitual conduct, what we do is largely determined by what we believe. Even habitual conduct often presupposes that certain beliefs have been accepted as true in the past. The world we live in is an interpreted world. The evidence for this is so massive that no one but philosophers would doubt it.

- Sidney hook, The Quest for Being, P.4 
https://ir.iba.edu.pk/businessreview/vol7/iss1/11

DOI: https://doi.org/10.54784/1990-6587.1307

Copyright of IBA Business Review is the property of Institute of Business Administration Karachi and its content may not be copied or emailed to multiple sites or posted to a listserv without the copyright holder's express written permission. However, users may print, download, or email articles for individual use. 